https://doi.org/10.30681/real.v14.4767

\title{
O MENINO NO ESPELHO E O ESPELHO DE NARCISO: LEITURA LITERÁRIA, IMAGINAÇÃO E EXPERIMENTAÇÃO DO MUNDO
}

\author{
Marcos Aparecido PEREIRA (IFMT) ${ }^{1}$ \\ Epaminondas de Matos MAGALHÃES (IFMT) ${ }^{2}$
}

\begin{abstract}
Resumo: Este trabalho busca discutir mediação de leitura literária na escola fazendo uma analogia com passagens da obra $O$ menino no espelho, de Fernando Sabino. Nesse sentido acreditamos que é preciso revisitar o mundo infantil, suas perspectivas, necessidades e, sobretudo, seus tipos de interação com o texto literário, afinal, apenas compreendendo que crianças e adolescentes são sujeitos ativos na construção de conhecimento é que seremos capazes de dialogar com seus repertórios de leitura e vivências, a fim de mediar novos encontros frutíferos no mundo da ficção. Percebemos que a escola é, ainda, vastamente pautada pelo discurso homogeneizador, fundamentado no saber legitimado pela crítica e/ou pelos manuais didáticos, quando o assunto é o que se deve ler. Assim, esquece-se que a leitura literária para crianças e adolescentes deve, primeiramente, ser capaz de encantar, de mobilizar, a partir de convenções compartilhadas, o universo psíquico e emocional desses.
\end{abstract}

Palavras-chave: Leitura literária. Mediação. Crianças. Adolescentes.

\begin{abstract}
This work seeks to discuss mediation of literary reading at school, making an analogy with passages from the book $O$ Menino no Espelho, by Fernando Sabino. In this way, we believe it is necessary to revisit the children's world, their perspectives, necessities and, above all, their types of interaction with the literary text, after all, only understanding that children and teenagers are active subjects in the construction of knowledge will we be able to dialogue with their reading repertoires and experiences, in order to mediate new prolific encounters in the world of fiction. We realize that school is still largely guided by the homogenizing discourse, based on the knowledge legitimized by the critic and/or by the didactic manuals, when the question is what should be read. Thus, it is forgotten that literary reading for children and adolescents must first be able to enchant, to mobilize, based on shared conventions, their psychic and emotional universe.
\end{abstract}

Keywords: Literary reading. Mediation. Children. Adolescents.

\section{Introdução}

A importância da leitura literária é debatida e defendida há muito tempo como uma prática imprescindível no que se refere ao autoconhecimento, autodesenvolvimento e consequentemente à humanização, como afirma Candido (2011). E quando o foco está nos

\footnotetext{
${ }^{1}$ Doutorando em Estudos Literários - PPGEL UNEMAT; Mestre em Ensino - IFMT; docente IFMT Campus Cáceres Prof. Olegário Baldo. E-mail: marcos.pereira@ cas.ifmt.edu.br

${ }^{2}$ Doutor em Letras PUCRS, docente IFMT Campus Pontes e Lacerda - Fronteira Oeste, PPGEN - IFMT e PPGEL - UNEMAT. E-mail: epaminondas.magalhaes@ plc.ifmt.edu.br
} 
estudantes, o aprimoramento das capacidades imaginativas, o estímulo à fantasia e o fortalecimento das potencialidades criativas de crianças e adolescentes são, sem sombra de dúvidas, benefícios ainda mais indispensáveis na opinião de teóricos e educadores.

Nesse contexto, estudos acerca do letramento literário e das práticas de leitura promovidas pela escola estão sempre entre os principais tópicos relacionados à formação e ao processo ensino-aprendizagem. Contudo, a despeito dos belos e bem fundamentados textos teóricos que defendem a leitura literária na escola, percebe-se que, no campo da prática, a grande maioria das experiências de leitura na escola acabam por distanciar os estudantes dos livros, seja pelo caráter de obrigatoriedade, seja pelo pouco espaço para escolhas livres e fora das recomendações de leitura dos manuais didáticos.

Os materiais didáticos são quase sempre "receitas" prontas a serem seguidas e, de acordo com Chiappini (2005), não favorecem a produção de conhecimento devido à homogeneização, à síntese e à simplificação dos assuntos e temáticas. E quando o assunto é leitura literária, a abordagem do livro didático é, em geral, ainda mais fragmentada, não favorecendo a real experimentação do texto literário, sua discussão e compartilhamento, entre os leitores, de olhares sobre as obras; ou seja, o trabalho com o texto literário mediado pelo livro didático, além de ser restrito à visão do autor do manual, delimita e baliza as leituras, tipos, gêneros, formas, etc. É nessa perspectiva que entendemos que a escola e o mediador da leitura, muitas vezes, agem como se quisessem reproduzir seus próprios reflexos, em se tratando do que deve ser lido, apreciado e discutido.

Desse modo, propomos uma reflexão acerca da prática do ensino de leitura literária por meio do romance de Fernando Sabino: $O$ menino no espelho. Essa reflexão parte do princípio de que essa obra pode ser utilizada em sala de aula como incentivo à leitura, à discussão de temáticas, experiências, ideias e maneiras de ver o mundo através da fantasia infantil; parte, também, da prerrogativa de que, ao interagir com o mundo infantil representado na obra, sejamos capazes de repensar as práticas de mediação literária, encontrar novos caminhos e maneiras de fazer com que estudantes e textos possam dialogar e, a partir de então, traçarem uma jornada de coexistência.

\section{Leitura literária e imaginação na infância e adolescência}

Zilberman (2008) explica que a leitura ajuda, por meio do ato de fantasiar e imaginar, a entender as próprias dificuldades, refletir sobre elas e buscar respostas para seus dramas. Em 
$O$ menino no espelho, por exemplo, as aventuras fantásticas do garoto Fernando podem estimular a imaginação de crianças e adolescentes, haja vista que o autor cria um mundo onde tudo é possível, basta acreditar e imaginar, do mesmo modo que acontece com o próprio ato da leitura.

A literatura é diversão e, também, formação, conhecimento sobre si mesmo e sobre o outro (MORLEY, 2007) estimulado por meio da imaginação. Dessa forma, tudo depende da identificação do leitor com o texto, independente da classificação e/ou da conceitualização dada a ele, afinal as produções artísticas formam "no conjunto uma massa de significados que influi em nosso conhecimento e nos nossos sentimentos" (CANDIDO, 2011, p. 184). Logo, a comparação de vários gêneros, estilos, autores, etc. serve para a construção do repertório de leitura que é rico na medida em que é heterogêneo.

Além disso, é preciso lembrar que "as pessoas são receptivas a partir de algo que já existe nelas de forma potencial e que encontra nesse fato uma oportunidade de se manifestar" (SALLES, 1998, p. 92). Portanto, quando uma obra consegue tocar o leitor é porque eles compartilham algo, porque o leitor aceitou o pacto imaginativo estabelecido pelo elemento estético e, pela identificação, fez sua parte no processo de co-criação da obra que se dá no ato da leitura (MORLEY, 2007). Desse modo, é a partir do diálogo imaginativo que "texto e leitor interagem a partir de uma construção do mundo e de algumas convenções compartilhadas" (COLOMER, 2003, p. 96), um processo de coexistência em que um dá sentido ao outro.

Desse modo, a mediação da leitura literária na infância e na adolescência requer um cuidado especial a fim de que esse processo de fato se concretize, afinal, é preciso que os estudantes se interessem pela leitura e consigam estabelecer um diálogo imaginativo com ela, tendo, como afirma Pennac (1998), os mesmos direitos que nós adultos nos damos: o de pular páginas, de não ler, de ler trechos aleatórios livremente, dentre outros. Ou seja, a leitura literária se abre, ganha vida e se fortalece num espaço de liberdade, de experimentação, de descoberta de rituais, um processo que, muitas vezes, a escola nega ao aluno.

A leitura literária mediada pela escola precisa ganhar espaço na vida do aluno dentro, mas principalmente fora da escola, de forma a contribuir para a busca autônoma de leituras (AGUIAR; BORDINI, 1988) a fim de criar um repertório de leitura. A leitura literária é processo de descobertas no qual determinados leitores consideram "que algumas narrativas existem como se tivessem sido feitas para eles, tamanho é o prazer que sentem na interação textual. Nesse caso, eles se apropriam dessas narrativas, transformando-as em referências em seu repertório" (PAULINO, 2000, p. 46). Assim, é preciso experimentar, errar, tentar 
novamente para, enfim, encontrar textos que sejam capazes de transformar-se em experiências frutíferas e duradouras na mente do leitor.

Outro ponto importante de ser lembrado é que não se força a imaginação e não se força a leitura, pois em ambas as situações os resultados são improdutivos. A livre imaginação cria, flui; a imaginação coagida seca, trava e, o mesmo, poderíamos dizer acontece com a leitura literária.

Nessa perspectiva, é importante compreender os interesses de leitura de cada idade, atentando-se para as finalidades de proposta de leitura, as fases de leitura em que o leitor se encontra, bem como as formas, assuntos, estilos dos textos sugeridos, como afirma Aguiar (1986). Afinal, a leitura só fará sentido e produzirá efeitos frutíferos e benéficos na vida do estudante se este for capaz de dialogar com a obra, transformando a leitura em experimentação, em vivência e em memórias, como acontece com o menino Fernando.

No romance de Sabino, o protagonista narrador, faz referência a Alice no País das Maravilhas, Tarzan, Robinson Crusoé e às criações do universo do famoso Sítio do Pica-Pau Amarelo, de Monteiro Lobato. Assim, o personagem Fernando deixa uma pista da importância das vivências no mundo da ficção literária no estímulo à imaginação, afinal, ao citá-los percebemos que esses são textos que, de alguma forma, marcaram sua existência. O menino, dessa forma, usa as histórias lidas e os heróis que admira como fonte de inspiração para construção de suas próprias aventuras e, também, como referências na tomada de decisões quando surge algum obstáculo, logo, ele utiliza as experiências da ficção como modelos em suas ações, deixando clara a influência, a necessidade e a importância que as mentiras ficcionais têm na vida das pessoas (LLOSA, 2016).

Além disso, é inegável que a principal caraterística daquele menino seja a imaginação, logo, é possível supor que essas obras mencionadas por ele e outras, possivelmente, fizeram parte de sua formação até aquele momento, uma formação que o leva a viver as mais divertidas e inusitadas aventuras que, por sua vez, oferecem campo fértil para as traquinagens imaginativas de outros jovens leitores. É o círculo virtuoso da literatura em que um livro leva a outro e outro e cujas experiências fortalecem, estimulam a imaginação e ajudam a formar, humanizar e a viver melhor, já que, embeleza e dá sentido ao mundo (TODOROV, 2009).

\section{A leitura literária na escola e o mito de Narciso}


A relação entre obra e leitor é uma relação fetichista, como diria Barthes (2004), logo, é uma experiência dialógica de autodescoberta pessoal, de vontades, interesses, sentimentos, ideias e emoções, afinal, o "objetivo [do leitor] é menos compreender o livro do que compreender a si mesmo através do livro" (COMPAGNON, 2003, p. 144). Esse processo é ainda mais evidente quando tratamos de crianças e adolescentes, uma vez que, nessas idades as pessoas buscam no livro tão somente o prazer de soltar a imaginação, de brincar com a fantasia, de se divertir com as experiências vividas no mundo da ficção. Desse modo, o texto literário precisa, obviamente, corresponder às expectativas de leituras dos leitores muito antes de corresponder às expectativas daqueles que indicam os livros para a leitura.

No prólogo da obra de Sabino, por exemplo, o menino encontra sua versão adulta, não o (se) reconhece, não sabe como ele surgiu ali no quintal, mas isso não o impede de mostrar as brincadeiras, o papagaio e, sobretudo, conversar com aquele "desconhecido". Assim, poderíamos propor uma analogia entre essa passagem e o ato da leitura, no que diz respeito às crianças: no geral, eles pouco ou nada se importam em saber quem é o autor da obra, como ela foi concebida, quais são suas qualidades intrínsecas; eles simplesmente dialogam com ela (ou não); eles assumem o “jogo livre, mas regulado, da imaginação" (SARTRE, 2004, p. 40) e tiram prazer, vivências e experimentações dessas interações.

O mundo adulto, o professor, a escola e os documentos oficiais que orientam a prática de leitura na escola, por sua vez, veem na leitura um fim, uma utilidade, como pode ser percebido no excerto: "as pessoas aprendem a gostar de ler quando, de alguma forma, a qualidade de suas vidas melhora com a leitura" (BRASIL, 1997, p. 29). Nessa perspectiva, o livro perde o seu primeiro combustível, sua energia vital e natural, especialmente no que se refere às crianças e aos adolescentes, de despertar a curiosidade, de proporcionar prazer, diversão e estabelecer um elo de comunicação discursiva, como diria Bakhtin (1997), com o mundo que se abre e se expande por meio da imaginação.

Além disso, por estabelecer-se naturalmente sobre uma relação fetichista, a leitura literária se afasta da obrigação, da imposição e da punição que, muitas vezes dão o tom das práticas de leitura em sala de aula. Não há prazer na obrigatoriedade, assim como "não se força uma curiosidade, desperta-se" (PENNAC, 1998, p. 121). Portanto, é preciso que a escola redescubra o valor da liberdade, respeitando a heterogeneidade de experiências, de gostos e de repertórios de leitura, como podemos perceber no fragmento a seguir:

Especialmente a leitura literária requer liberdade, cujo único limite é o respeito pela leitura do outro, que pode apresentar suas singularidades. As preferências de cada um são respeitadas para que ocorra de fato uma leitura 
literária. Como a escola tende a homogeneizar comportamentos, o cuidado das autoridades nesse primeiro momento se torna fundamental. Posteriormente, a mediação docente que não reprima, mas incite a imaginação de cada aluno no pacto com o texto, também constitui um componente essencial do processo escolarizado de leitura literária. (PAULINO, 2017, online, grifo nosso).

De acordo com Sartre (2004), a leitura literária é comparada a um sonho livre, no qual é preciso que o leitor aceite o pacto estabelecido pela obra e deseje aventurar-se nela. Assim, crianças preferem histórias que tenham fantasia, mundos mágicos e aventuras, já os adolescentes são mais facilmente cativados pela leitura quando elementos como o medo, o mistério, a aventura, o desafio e a curiosidade estão presentes na narrativa. Isso posto, "aquilo que não divertir, emocionar ou interessar ao pequeno leitor, não poderá também transmitir-lhe nenhuma experiência duradoura ou fecunda" (COELHO, 1997, p. 145). Por isso é preciso que o professor saiba perceber as fases e os possíveis interesses de leituras de seus alunos a fim de indicar e discutir determinadas obras em sala de aula (AGUIAR, 1986).

O menino Fernando, no romance, passa por aventuras e experiências que assim como os sonhos são importantes na sua formação psíquica. Ele aprende valores, supera medos, comete erros, estabelece relações com o mundo e através de um processo de alteridade descobre-se. É preciso lembrar, ainda, que tudo isso de forma espontânea, em forma de brincadeira, de peraltices e vivências infantis mediadas pela imaginação que, obviamente, resultam em aprendizado. Esse aprendizado, por sua vez, não pode ser controlado, haja vista que as pessoas percebem, sentem, agem e interagem diferentemente.

O mesmo acontece com a leitura literária, pois cada obra toca o leitor de uma maneira única em determinado momento de sua vida, desse modo, os resultados da interação obra-leitor não podem ser previstos com exatidão. Leitura literária não é experiência ordenada, exata, regulada. Não há como medir com exatidão os efeitos da leitura em cada leitor, assim como não se podem medir os sonhos. Por isso a literatura foi e é vista como perigosa, afinal, ela é "uma aventura que pode causar problemas psíquicos e morais" (CANDIDO, 2011, p. 178), pois, "[a leitura] como toda experiência implica riscos, para o leitor e para aqueles que o rodeiam" (PETIT, 2013, p. 147).

A imaginação talvez seja a mais poderosa das faculdades humanas e o seu desenvolvimento, a partir da infância, passa por experiências como as brincadeiras, as leituras, os filmes ou desenhos animados etc. De acordo com Chartier (2009), desde a revolução industrial, a leitura literária tem sido preocupação daqueles que lidam com a formação. Assim, o trabalho de indicação do que se deve ler sempre preocupou a escola, fazendo surgir "receitas" 
e manuais que, muitas vezes, são reproduzidos pelos professores de forma dogmática. Afinal, com o surgimento do livro didático, o professor deixa de ser o intelectual, pede-se, apenas que ele reproduza, não que pense (CHIAPPINI, 2005). Talvez por isso esqueceu-se de que "estudar literatura não é só ler os textos consagrados pela tradição da história da literatura brasileira, por exemplo" (CHIAPPINI, 2005, p. 115).

Acreditamos, entretanto, que o trabalho de mediação de leitura literária na escola deve estar atento às preferências de leitura de cada idade e não se limitar às recomendações da crítica e/ou dos manuais didáticos. O professor precisa estar aberto ao novo e aprender a dialogar em sala de aula com novas leituras oriundas do universo cultural de seus alunos e, a partir delas, ser capaz de mediar novas experimentações. Rosemar Coenga, ao tratar dessa temática, destaca que "a distância entre o jovem e a leitura pode ser minimizada se a atividade for prazerosa. Para promover esse encontro amoroso, é necessário, antes de tudo, sensibilidade e coerência" (COENGA, 2010, p. 103).

A sala de aula é sempre múltipla e heterogênea e reconhecer essas peculiaridades não é fácil, requer tempo, experimentação e, principalmente, diálogo aberto e sincero. Assim, é importante o incentivo à leitura de gêneros receptivos a determinada série e/ou idade, mas também atenção às transformações individuais ao longo do processo, haja vista que as preferências de leitura mudam tanto com a idade (que nem sempre é a cronológica) quanto com a experiência individual, o que, se por um lado exige um esforço grande do mediador de leitura, por outro abre possibilidades e espaços de interação com diversos gêneros e estilos ao longo do processo, desde que haja receptividade dos estudantes.

Acrescenta-se, ainda, que as relações com as diferentes obras e/ou gêneros têm densidades e momentos distintos para o leitor, sendo que há uma idade para cada tipo de leitura e que todas elas são importantes (CALVINO, 1993). Portanto, é imprescindível que o leitor seja capaz de dialogar com diferentes obras, em condições e momentos distintos da vida. Contudo, na prática, a escola, comumente, reproduz discursos prontos dos manuais didáticos e/ou da crítica literária, foca em periodização e historiografia literária e dá pouco espaço para a livre experimentação, para a leitura e discussão aberta de obras e autores durante as aulas.

Assim, não é raro perceber que a escola e, consequentemente, o mediador da leitura literária age como um Narciso olhando sua imagem no lago. Se, ao olhar para o próprio reflexo, o personagem do mito tem a possibilidade de se reconhecer, identificar-se, no momento seguinte, ao não levantar o olhar e encarar o mundo ele submerge; assim, em nossa analogia, hipnotizado pela própria beleza e/ou pela certeza das próprias crenças (e receitas), perde 
completamente o contato com o mundo a sua volta, no caso os alunos, e morre afogado junto com as próprias crenças. Portanto, uma prática de incentivo à leitura que não saiba olhar para as especificidades do leitor, seu repertório de leitura, preferências, tende a submergir no reflexo das belas palavras da teoria.

Desse modo, a mediação literária que não abre espaço para o diferente, especialmente para aquilo que não foi legitimado pela crítica e/ou pelo livro didático e que, portanto, não leva em conta as experiências, necessidades e vivências de crianças e adolescentes não é uma "mediação" no cerne do termo, pois não olha no olhar do outro, vê apenas a si mesma. Notar o olhar de encantamento, ou não, das crianças e adolescentes deveria ser o principal termômetro do mediador da leitura literária na escola, pois o olhar do outro revela mais de sua verdade que qualquer teoria ou recomendação.

A leitura literária é bela, a literatura é direito humano e cumpre as três funções propostas por Candido (2011), atuando diretamente no nosso subconsciente, levando-nos a sonhar acordados e a refletir sobre nós mesmos e sobre nossas interações sociais, o que, por sua vez, está intrinsecamente relacionado com a nossa formação (e transformação) humana. Contudo, a partir do momento em que os mediadores da leitura e a escola ficam seduzidos pela beleza das próprias teorias, pela grandiosidade de textos laureados e/ou dos efeitos e do prazer que devem ser "ensinados", esquecendo-se de que o aluno pensa, sente e age de outra forma, a mediação literária faz com que o processo submerja e morra como Narciso olhando no lago. É imprescindível ter em mente que a resposta do aluno frente ao texto proposto pode ser divergente daquela esperada, pois os efeitos provocados, por exemplo, no mediador podem não se repetir nos estudantes.

Uma boa prática de mediação de leitura, leva em conta, primeiramente, o leitor, especialmente se esse for criança ou adolescente, afinal eles não são apenas receptores são sujeitos ativos dentro de um processo dialógico de aprendizagem. Desse modo, o mediador do texto literário precisa saber atender às expectativas de leitura e ampliar os horizontes de expectativas dos jovens leitores (AGUIAR; BORDINI, 1988). Do contrário, castra-se a liberdade de leitura e emoldura-se e sacraliza-se a literatura, uma prática que desencoraja as buscas autônomas dos estudantes, aquelas que estão além dos muros e das exigências da escola.

Desse modo, a escola precisa deixar de ser um espelho que reflete apenas práticas legitimadas pelo livro didático e/ou pela crítica, que elege obras "significativas", mas que, muitas vezes, não são capazes de mobilizar os estudantes (nem intelectualmente, nem emocionalmente). Logo, é preciso que a escola passe a ser espaço de diálogo e troca, afinal, 
independentemente da classificação da obra, no ato da leitura, o leitor é chamado a "ir além da coisa escrita. Sem dúvida, o autor o guia, mas somente isso; as balizas que colocou estão separadas por espaços vazios, é preciso interligá-las, é preciso ir além delas" (SARTRE, 2004, p. 38). Portanto, o leitor só seguirá adiante, de bom ânimo, preenchendo os espaços com imaginação, através de uma interação que lhe seja agradável, visto que, segundo Barthes (2004), a leitura é penetrada de desejo e repulsa.

Mediar as relações de repulsa e de desejo, as diferenças de compreensão, de vivências e de repertório de leitura dentro da escola é outro desafio que se abre, afinal, sobre o professor paira uma autoridade imaginária de detentor do conhecimento e talvez por isso a escola, como um todo, rejeite aquilo que não foi previamente prescrito, que não passou pelo aval dos manuais didáticos e que não foi "permitido" ensinar. Logo, os manuais espelham o que crítica, embasada na teoria, apregoa; os professores, por sua vez, espelhando os dizeres dos manuais, querem que os alunos sejam o reflexo deles mesmos [os professores], apreciando o que eles reconhecem como "bom". Essa é uma reação em cadeia que, aparentemente, não tem tido o êxito esperado, sobretudo numa época de interações dinâmicas, multifacetadas, heterogêneas, rápidas, fragmentadas e inconstantes. Desse modo, é preciso que a escola se transforme num espaço de troca, de debate, de reflexão e de aprendizado a partir do diálogo.

\section{Fernando Sabino e $O$ menino no espelho}

O escritor brasileiro Fernando Sabino produziu aproximadamente cinquenta obras. Dotado de uma escrita leve, rápida e cativante, ele publica $O$ menino no espelho pela primeira vez em 1982 e apresenta um universo facilmente possível de ser relacionado com as suas próprias experiências de infância, uma vez que o personagem é homônimo e que antes do sumário, como apresentação do livro, há uma foto dele, ainda criança. Assim, poderíamos filiar o movimento desenvolvido por Sabino nessa obra com a teoria de Lejeune (2014), que na contramão da hermenêutica estruturalista trabalha com os conceitos de autobiografia e autoficção. Contudo, a despeito de ser ou não reminiscências da infância autor, nos interessa, sobremaneira, as possibilidades de reflexão do personagem com o mundo, mediadas pela imaginação.

O romance é composto de doze pequenas histórias, os capítulos formam-se quase como se fossem contos, mas que possuem sequência cronológica e articulam-se de maneira a formar uma única narrativa, cujo escopo talvez seja demonstrar as potencialidade e a 
importância de ato de imaginar no processo de formação do ser humano (adulto). Assim, de forma singela, Sabino expõe um processo de desenvolvimento de habilidades emocionais, cognitivas e sociais do personagem.

Fernando, o protagonista, experimenta um mundo fantástico onde as aventuras têm o limite da fantasia, ou seja: nenhum. Assim, ele é capaz de fazer milagres, desaparecer, voar, duplicar-se, etc. E ao contar suas histórias ele leva o leitor a acreditar que elas verdadeiramente foram e são possíveis, desde que a pessoa se entregue completamente ao mundo da imaginação.

Impossível não estabelecer uma analogia com o próprio ato da leitura literária, no qual, assim como Fernando, nos transformamos em agentes-secretos, superamos os desafios de uma floresta, experimentamos as belezas e as dificuldades do amor, ou seja, nos transformamos através da experimentação possível pela imaginação.

Além disso, é possível destacar os aspectos de interação social e amizade nítidos na relação de Fernando com outros personagens: primeiro com a galinha Fernanda, depois com a amiga Mariana, com o irmão Gerson, que o ensina a jogar futebol, e até com Godofredo, o papagaio, Pastoff, o coelho, e Hindemburgo, o cachorro. Desse modo, o personagem expõe a importância das relações infantis com o mundo à sua volta, pois é na interconexão com esses seres, humanos ou não, que a criança vai, aos poucos, tomando consciência de si e formando sua própria personalidade.

Além disso, gostaríamos de destacar o capítulo A libertação dos passarinhos, onde Fernando e Mariana, decidem soltar todas as aves que estavam presas nas gaiolas do vizinho. A travessura dos dois é impulsionada por, basicamente dois sentimentos: compensar a morte acidental de um passarinho que eles, por curiosidade, abriram as vísceras e acabaram com remorsos; e, ainda, querer se vingar do vizinho que acaba se transformando num tipo de inimigo dos pequenos. Entretanto, para além dos sentimentos dos personagens, podemos compreender que simbolicamente os pássaros representam a liberdade e a independência e, nesse caso, podem ser relacionados à imaginação, sugerindo a liberação da imaginação e da fantasia, tão características da infância.

Desse modo, quando os pássaros voltam rodopiando no ar antes de formar uma "linha reta, afastando-se como uma nuvem multicor até desparecer em direção ao infinito" (SABINO, 2020, p. 163), o texto apresenta-nos uma metáfora da imaginação que gira em torno de nós, depois eleva-se e expande-se, incontrolável, impalpável, ganhando cores e formas multicoloridas num processo sem limites. Assim, passado e presente se encontram, as memórias do personagem se misturam com a imaginação e criam um mundo fantástico capaz de mobilizar 
a ele e, também ao leitor que compartilhar das mesmas convenções, como diria Colomer (2003), um processo que não pode ser controlado e que ganha vida, de forma única, na psique de quem lê, confirmando o caráter mágico da leitura literária.

\section{CONSIDERAÇÕES}

A escola, sua forma moderna, sempre teve preocupação com o que crianças e adolescentes estavam lendo, por considerar que o desenvolvimento e o aprimoramento da imaginação fazem parte da essência do processo ensino-aprendizagem. Contudo, apesar das boas intenções, a mediação da leitura literária fundamentada nesse cuidado didático gerou (e gera) "recomendações" impositivas do que deveria ser lido e apreciado pelos estudantes.

Nesse viés, esquece-se que o prazer não pode ser ensinado, que crianças e adolescentes têm suas peculiaridades, suas perspectivas de mundo e, portanto, comumente, não estão em sintonia com obras laureadas pela crítica e/ou manuais; logo, ao ler por obrigação, o único efeito produzido pode ser o afastamento e a esterilidade da busca autônoma. Esse tipo de busca, destaca-se, deveria ser um dos principais incentivos que a escola poderia ensinar, afinal, a escola eficiente educa para além dela mesma.

Leitura literária é amadurecimento, e cada um descobre os caminhos mágicos do livro por meio de gêneros, autores e estilos diferentes. Desse modo, a escola precisa quebrar preconceitos e trazer para as aulas o compartilhamento de experiências dos estudantes e, a partir desse compartilhamento, ser capaz de delinear novos caminhos, expandir horizontes e ampliar repertórios. É preciso romper com o foco único do conhecimento legitimado e fundar o intercâmbio de saberes, afinal é no diferente, no conflitante, no composto que a aprendizagem nasce, se fortalece e se multiplica.

Constata-se, também, que, em termos teóricos a escola está muito bem amparada, mas na prática ainda há muito trabalho a ser feito a fim de romper as barreiras do tratamento inadequado dado ao texto literário e das recomendações solidificadas de leitura, especialmente para crianças e adolescentes. Carecemos de espaços de discussão e compartilhamento de experiências de leitura e olhares que se cruzam, se conectam e se reproduzem na diversidade, na heterogeneidade de discursos, formas e cores que dão sabor ao mundo.

\section{REFERÊNCIAS}


AGUIAR, Vera Teixeira. Leituras para o $1^{\circ}$ grau: critérios de seleção e sugestões. IN: LAJOLO, Marisa [et al]. Leitura em crise na escola: as alternativas do professor. Porto Alegre: Perspectivas, 1986.

AGUIAR, Vera Teixeira de; BORDINI, Maria da Glória. Literatura: a formação do leitor: alternativas metodológicas. Porto Alegre: Mercado Aberto, 1988.

BAKHTIN, Mikhail. Problemas da poética de Dostoievski. Rio de janeiro: Forense Universitária, 1997.

BRASIL. Parâmetros Curriculares Nacionais: Língua Portuguesa. Secretaria de Educação Básica. - Brasília: Ministério da Educação, Secretaria de Educação Básica, 1997.

CALVINO, Ítalo. Por que ler os clássicos. São Paulo: Cia das Letras, 1993.

CANDIDO, Antonio. Vários escritos. Rio de Janeiro: Ouro sobre Azul, 2011.

CHARTIER, Roger. A aventura do livro: do leitor ao navegador. São Paulo, Editora UNESP, 2009.

CHIAPPINI, Ligia. Reinvenção da Catedral: língua, literatura, comunicação: novas tecnologias e políticas de ensino. São Paulo: Cortez, 2005.

COELHO, Nelly Novaes. Literatura Infantil: teoria, análise e didática. São Paulo: Moderna, 1997.

COENGA, Rosemar. Literatura e letramento literário: diálogo. Cuiabá: Carlini \& Caniato, 2010.

COLOMER, Teresa. A formação do leitor literário: narrativa infantil e juvenil atual. São Paulo: Global, 2003.

COMPAGNON, Antoine. O leitor. In: . O demônio da Teoria. Belo Horizonte: UFMG, 2003.

LEJEUNE, Philippe. O pacto autobiográfico: de Rousseau à Internet. Org. NORONHA, Jovita Maria G. Belo Horizonte: UFMG, 2014.

LLOSA, Mario Vargas. La verdad de las mentiras. Livro digital. Alfaguara, 2016.

MORLEY, David. Creative Writing. New York: Cambridge University Press, 2007.

PAULINO, Graça. Leitura literária. Glossário CEALE. Disponível em http://ceale.fae.ufmg.br/app/webroot/glossarioceale/verbetes/leitura-literaria. Acesso em: 14 jun. 20.

PAULINO, Graça. Diversidade de narrativas. In: PAIVA, Aparecida et. al. (Orgs.). No fim do século: a diversidade do jogo do livro infantil e juvenil. Belo Horizonte: Autêntica, 2000.

PENNAC, Daniel. Como um romance. Rio de Janeiro: Rocco, 1998. 
PETIT, Michèle. Os jovens e a leitura: uma nova perspectiva. São Paulo: Editora 34, 2013.

SALLES, Cecilia Almeida. Gesto inacabado: processo de criação artística. São Paulo: FAPESP, 1998.

SARTRE, Jean-Paul. O que é a literatura? São Paulo: Ática, 2004.

TODOROV, Tzvetan. A literatura em perigo. Rio de Janeiro: DIFEL, 2009.

ZILBERMAN, Regina; SILVA, Ezequiel Theodoro. Literatura e pedagogia: ponto e contraponto. São Paulo: Global, 2008. 